\title{
Phenotypic diversity in patients with multiple serrated polyps: a genetics clinic study
}

\author{
Daniel D. Buchanan • Kevin Sweet • Musa Drini • Mark A. Jenkins • Aung Ko Win • \\ Michael Gattas • Michael D. Walsh • Mark Clendenning • Diane McKeone • \\ Rhiannon Walters • Aedan Roberts • Alasdair Young • Heather Hampel • \\ John L. Hopper • Jack Goldblatt • Jill George • Graeme K. Suthers • Kerry Phillips • \\ Graeme P. Young • Elizabeth Chow • Susan Parry • Sonja Woodall • Kathy Tucker • \\ Amanda Muir • Michael Field • Sian Greening • Steven Gallinger • Jane Green • \\ Michael O. Woods • Renee Spaetgens • Albert de la Chapelle • Finlay Macrae • \\ Neal I. Walker • Jeremy R. Jass • Joanne P. Young
}

Accepted: 14 January 2010 /Published online: 6 March 2010

(C) The Author(s) 2010. This article is published with open access at Springerlink.com

\begin{abstract}
Objective Hyperplastic polyposis is a colonic polyposis condition of unknown aetiology. The purpose of this study was to examine the spectrum of phenotypic variation in patients with multiple serrated polyps as a basis for gene discovery.

Methods One hundred and twenty-six patients with multiple $(\geq 5)$ serrated polyps were recruited to the study. Polyp counts were extracted from histology and colonoscopy reports. Ethnicity was self-reported. Family history of cancer data were derived from pedigrees. Ascertainment status was classified as either index case or identified by screening.
\end{abstract}

D. D. Buchanan $\cdot$ M. D. Walsh $\cdot$ M. Clendenning $\cdot$ D. McKeone

R. Walters $\cdot$ A. Roberts $\cdot$ J. P. Young $(\bowtie)$

Familial Cancer Laboratory, QIMR,

Herston, Brisbane Q 4006, Australia

e-mail: Joanne.Young@qimr.edu.au

D. D. Buchanan $\cdot$ M. D. Walsh $\cdot$ J. P. Young

School of Medicine, University of Queensland,

Herston, Brisbane Q 4006, Australia

K. Sweet $\cdot$ H. Hampel $\cdot$ A. de la Chapelle

Division of Human Genetics, Ohio State University,

Columbus, OH 43221, USA

M. Drini $\cdot$ F. Macrae

Department of Colorectal Medicine and Genetics,

The Royal Melbourne Hospital,

Parkville, Melbourne, VIC 3050, Australia

M. A. Jenkins $\cdot$ A. K. Win · J. L. Hopper

Centre for MEGA Epidemiology, School of Population Health,

University of Melbourne,

Carlton, Melbourne, VIC 3053, Australia
Results The average reported polyp count was 39. Patients with highest polyp numbers were more likely to be male $(P=0.02)$. Colorectal cancer (CRC) was identified in 49 of 119 patients $(41 \%)$ and $28 \%$ of these patients had multiple CRC. Young onset patients had higher polyp numbers $(P=$ 0.03 ) and were more likely to have their CRC in the distal colon $(P=0.02)$. $\mathrm{CRC}$ was significantly associated with the presence of adenomas $(P=0.03)$. Patients were divided into moderate polyposis (5-79 serrated polyps) and dense polyposis ( 80 or more) categories. The dense polyposis category was associated with a lack of family history for

M. Gattas

Queensland Clinical Genetics Service, Royal Children's' Hospital, Herston, Brisbane Q4029, Australia

A. Young

St Pauls School,

Strathpine Road, Bald Hills,

Queensland, Australia

J. Goldblatt $\cdot$ J. George

Genetic Services of Western Australia,

Subiaco, Perth WA 6008, Australia

J. Goldblatt

School of Paediatrics and Child Health University

of Western Australia,

Nedlands, Perth WA 6009, Australia

G. K. Suthers $\cdot$ K. Phillips

South Australian Clinical Genetics Service,

North Adelaide SA 5009, Australia 
CRC $(P=0.034)$ and male gender $(P=0.014)$, independent of ascertainment status and recruitment site.

Conclusion Multiple serrated polyps were associated with an increased personal risk of CRC. A subset of patients with the highest polyp numbers was more likely to be male and to have no family history of CRC. This result suggests heterogeneous modes of inheritance and has implications for studies investigating the genetic basis of multiple serrated polyps.

Keywords Hyperplastic polyposis · Serrated neoplasia . Smoking $\cdot$ Family history $\cdot$ Ethnicity

\section{Introduction}

The recognition of the serrated neoplasia pathway has facilitated investigation of the aetiology of the remaining unexplained portion of familial colorectal cancer (CRC) [1, 2]. Analogous to the multiple adenoma syndromes familial adenomatous polyposis and $M U T Y H$-associated polyposis, individuals with hyperplastic polyposis syndrome (HPS) also develop CRC on a background of multiple polyps throughout the colon but in contrast, most of the polyps in HPS demonstrate serrated morphology. HPS was first described in 1977 by Spjut and Estrada [3], frequently presents with features consistent with a genetic predisposition to CRC [4], and is currently defined by the World Health Organization (WHO) criteria as

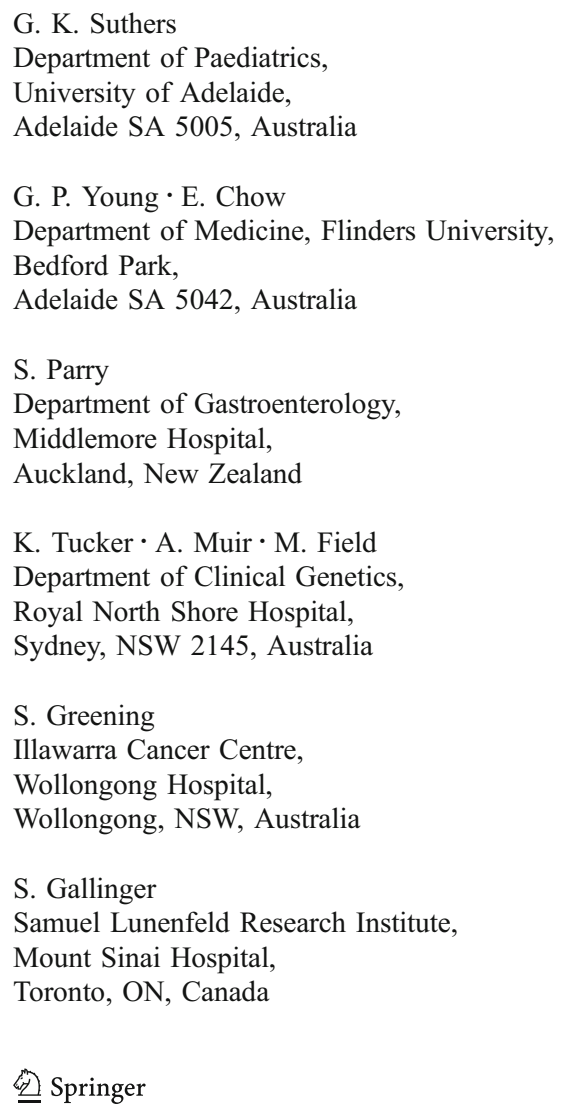

1) at least five histologically diagnosed hyperplastic polyps proximal to the sigmoid colon, two of which are greater than $10 \mathrm{~mm}$ in diameter OR

2) any number of hyperplastic polyps occurring proximal to the sigmoid colon in an individual who has a firstdegree relative with hyperplastic polyposis OR

3) more than 30 hyperplastic polyps of any size but distributed throughout the colon [5].

The WHO criteria were originally introduced to distinguish HPS from the common observation of satellite hyperplastic polyps around rectal cancers and diminutive distal colon lesions, and to highlight observations that even small numbers of larger hyperplastic polyps in the proximal colon may be associated with increased malignant potential [6]. However, because such definitions are necessarily stringent and somewhat arbitrary, many individuals and families with multiple hyperplastic polyps will fall short of these criteria [7]. Since the publication of the criteria in 2000 , several investigators have proposed modifications to address these limitations. Higuchi and Jass have suggested that atypical serrated polyps (these include sessile serrated adenomas, serrated adenomas and mixed polyps) be included in the total polyp count which can be cumulative over time [8]. Variations on the threshold polyp count have been proposed, with Chow et al. [9], Rashid et al. [10], Hyman et al. [11], and Boparai et al. [12], all favouring a count of 20 hyperplastic polyps, and Carvajal-Carmona [13] using ten, instead of a count of 30 as described by the criteria.

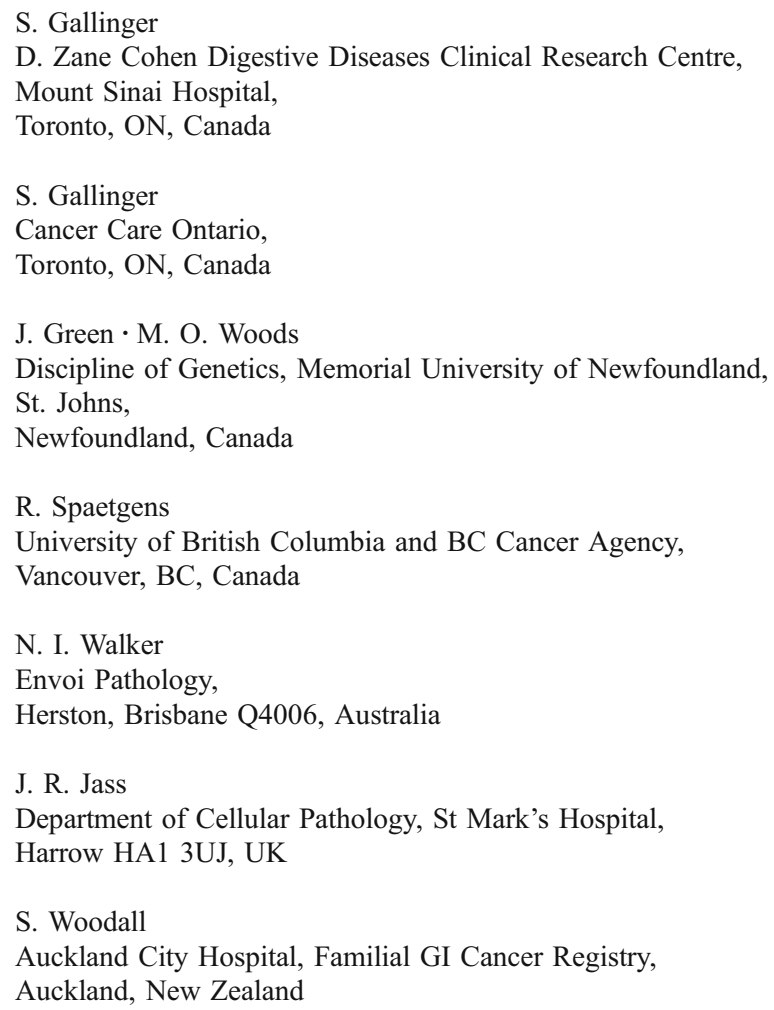


As reflected in the WHO criteria, HPS presents with extensive phenotypic heterogeneity not only with respect to the number and size of polyps, but also with regard to presence of CRC, polyp histology, sex ratios, age of onset, and the presence of a family history of CRC [10, 14-22] (Table 1). The underlying basis for the observed phenotypic heterogeneity is currently unclear; however, an analysis of phenotype in a large series of high-risk patients with multiple serrated polyps may contribute to our understanding of this heterogeneity by identifying patterns of inheritance and relationships between clinical features. In this, the largest such patient group studied to date, we examined the spectrum of presentations as an initial step to establishing a modern classification for this condition upon which to base gene discovery programmes, a procedure best carried out in a high-risk population.

\section{Patients and methods}

The use of the term serrated polyp in this report encompasses any polyp with serrated architecture [23], and includes both common (hyperplastic or metaplastic) and advanced (serrated adenoma, sessile serrated adenoma, and mixed polyp) lesions. Due to the limitations of the WHO criteria, this cross-sectional study comprised 126 patients with multiple serrated polyps (five or more) recruited from genetics clinics in Australasia $(n=94)$ and North America $(n=32)$ regardless of family history of polyps and cancer. Using this approach which targets high-risk patients, we are unlikely to have recruited elderly patients with common distal serrated polyps, whilst at the same time recruiting patients with clinically significant disease who may have fallen short of the current WHO criteria. Thirty-eight patients from Australasia and ten from North America have been reported previously [9, 24]. Clinical and pathology data were extracted from histology reports, minimum polyp counts were derived from serial colonoscopy reports, where available, accounting for polyps removed at each procedure. Patients with polyps demonstrating hamartomatous features were not included in the study. Smoking status was recorded as never/ever and note was made of whether the participants were currently smoking. Patients gave written informed consent to participate in the research. The study was approved by the Human Research Ethics Committee (HREC) of Queensland Institute of Medical Research under the Genetics of Serrated Neoplasia project (QIMR HREC Protocol P912). Self-reported paternal and maternal ethnicity was recorded where available. Colorectal cancers were verified in first-degree relatives (parents, children, and siblings of the proband) using histology reports. Where more than one instance of multiple serrated polyps was present in a family, family history used the youngest proband as a point of reference $(n=6)$. In 118 families, we were

Table 1 Published series of HPS cases where $\mathrm{n}$ was greater than five individuals, highlighting the phenotypic diversity of HPS

\begin{tabular}{|c|c|c|c|c|c|c|c|c|}
\hline Author & Year & $\begin{array}{l}\text { Cases } \\
\text { HPS }(n)\end{array}$ & $\begin{array}{l}\text { Mean age at } \\
\text { diagnosis (years) }\end{array}$ & $\begin{array}{l}\text { Males } \\
(\%)\end{array}$ & $\begin{array}{l}\text { Number of polyps } \\
\text { observed }\end{array}$ & $\begin{array}{l}\text { CRC } \\
(\%)\end{array}$ & $\begin{array}{l}\text { CRC in proximal } \\
\text { colon }(\%)\end{array}$ & $\begin{array}{l}\text { Family } \\
\text { history } \\
\text { of CRC } \\
(\%)\end{array}$ \\
\hline Buchanan $^{a}$ & 2009 & 126 & 49 & 50 & $5-150$ & 40 & 59 & 59 \\
\hline Boparai [12] & 2009 & 77 & 56 & NS & $2-53$ & 35 & NS & NS \\
\hline Chow [9] & 2006 & 38 & 44 & 55 & Multiple & 26 & 40 & 50 \\
\hline $\begin{array}{l}\text { Carvajal- } \\
\text { Carmona [13] }\end{array}$ & 2007 & 32 & 46 & 66 & multiple & 25 & NS & 59 \\
\hline Renaut [19] & 2001 & 28 & 58 & 54 & Multiple & 29 & NS & 39 \\
\hline Yeoman [40] & 2007 & 24 & 61 & 42 & Multiple & 54 & 84 & 17 \\
\hline Ferrandez [15] & 2004 & 15 & 53 & 66 & Multiple & 0 & NS & 0 \\
\hline Lage [16] & 2004 & 14 & 58 & NS & $19-100$ & 43 & 67 & 33 \\
\hline Hyman [11] & 2004 & 13 & 62 & 38 & Multiple & 54 & 71 & 38 \\
\hline Rashid [10] & 2000 & 13 & 58 & 54 & Multiple & 77 & NS & 38 \\
\hline Leggett [17] & 2001 & 12 & 57 & 42 & 30 to $>100$ & 58 & NS & 17 \\
\hline Rubio [20] & 2006 & 10 & 61 & 80 & $6-159$ & 70 & 43 & 10 \\
\hline Spjut [3] & 1977 & 9 & 53 & NS & Multiple & 11 & NS & NS \\
\hline Williams [21] & 1980 & 7 & 37 & 86 & $50-150$ & 0 & NS & 14 \\
\hline Torlakovic [30] & 1996 & 6 & 57 & 83 & $50-100$ & 67 & NS & NS \\
\hline Place [18] & 1999 & 6 & 60 & 100 & $50-100$ & 50 & 100 & 14 \\
\hline
\end{tabular}

NS not specified; multiple upper limit of polyp numbers not specified

${ }^{\text {a }}$ Current manuscript data 
able to classify patients as either index cases (the initial presenting family member $n=89$ ) or screening cases (where multiple serrated polyps were identified as a result of screening due to family history of colonic neoplasia, $n=32$ ). All but two index cases presented due to abdominal symptoms (bleeding, pain, or change in habit). The remaining two cases were diagnosed as an incidental finding during investigations for a hernia repair and an incidental finding at population screening due to age, respectively. Polyp counts in the entire study group, as well as in index cases showed a bimodal distribution and fell into two groups (Fig. 1) about a cut-point polyp count of 80 , and were classified as either moderate polyposis ( $<80$ polyps) or dense polyposis ( $\geq 80$ polyps). All screening cases were observed to be in the moderate polyposis group.

\section{Statistical analysis}

The associations between categorical predictor variables were assessed for statistical significance using an exact chi-squared test and odds ratios where appropriate. Comparison of means for age and minimum polyp count data were made using $t$ tests. Missing data were excluded from the analysis. Multivariate analysis was used for estimating the odds ratios and 95\% confidence intervals for the association between variables and two categorical outcomes of polyp number (moderate versus dense polyp count). All $P$ values were two-sided and a $P$ value $<0.05$ was considered as statistically significant. SPSS version 17 was used for all statistical analysis. In order to limit the effects of ascertainment bias, any significant findings were re-analysed in the subset of index cases.

\section{Results}

Characteristics of multiple serrated polyp patients

Table 2 shows that approximately one-half of patients were female (one patient unreported gender), and almost all were of Northern European ancestry, predominantly English, Irish, Scots, Welsh, French or French-Canadian, German, Swedish and Dutch. Six patients (5\%) reported Italian, Greek or Middle-eastern ancestry (two of each). Two patients reported Anglo-Maori and Anglo-Middle-eastern ethnicity, respectively, and a third patient had a Jamaican parent. Two patients from a single family reported European-Russian-Jewish ancestry.

Patients from North America did not differ significantly from patients from Australia with respect to rates of CRC. CRC was diagnosed in $41 \%$ of patients, the majority of which were proximal (CRC site could not be confirmed in eight patients). Nine of the 24 patients (38\%) with a proximal CRC had multiple (two to four) CRCs in the proximal colon and all but one of these were synchronous (Table 3). Multiple proximal CRCs were divided equally between males and females. No multiple CRCs were seen within in the distal colon; however, a further two patients had both a proximal and a distal CRC. Overall, 11 of 40 patients had multiple CRC (28\%). Females with CRC were more likely to present with proximal malignancy than with distal CRC, whilst males with CRC were evenly divided between sites.

There was no significant difference in mean age at presentation between the sexes $(P=0.98)$, or between patients with and without CRC $(P=0.91)$, however, patients presenting with $\mathrm{CRC}$ before age 50 were significantly more
Fig. 1 Frequency of polyp count numbers showing the distribution of polyp counts in a bimodal pattern about a polyp count of 80 and a concentration of screening cases below this number

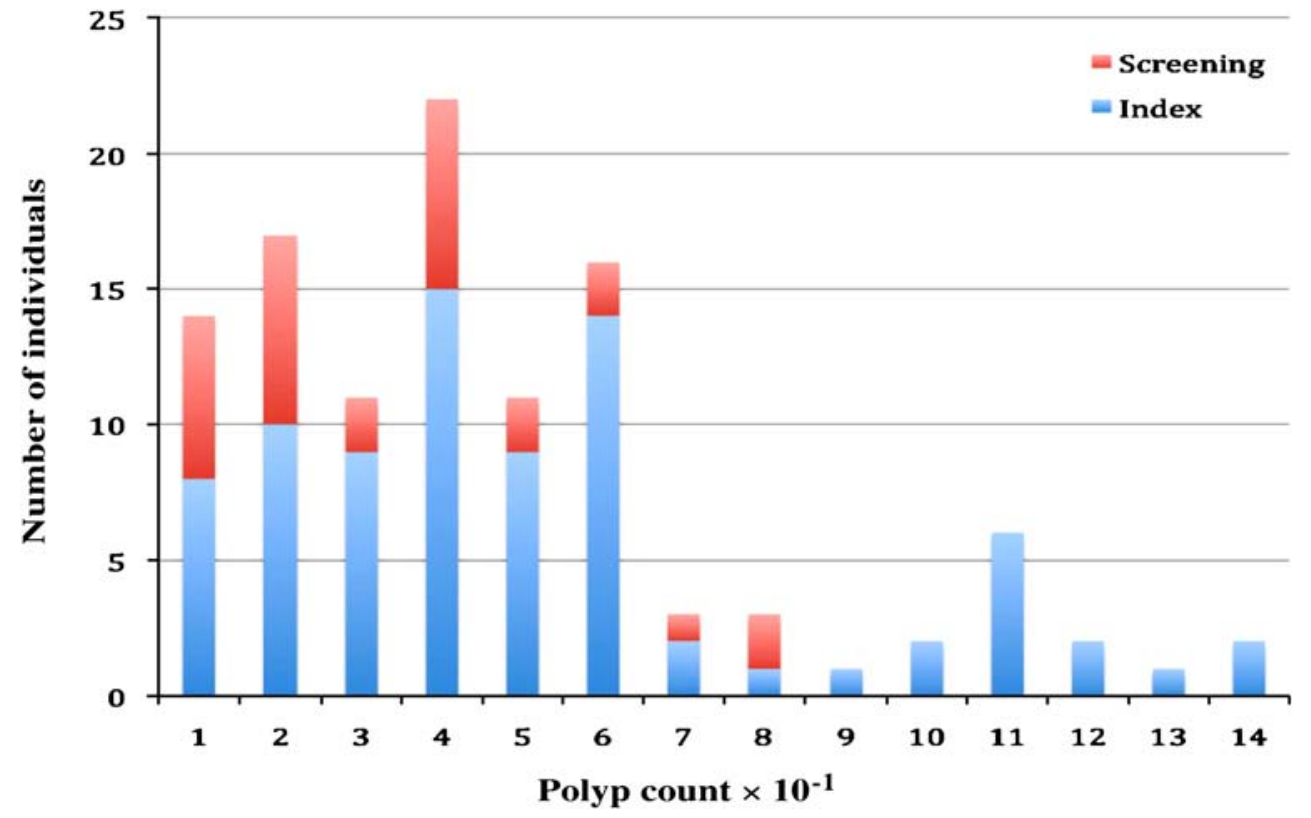


Table 2 Baseline characteristics of the participants in the study

\begin{tabular}{|c|c|c|c|}
\hline Characteristic & Number/mean (SD) & Total & Percentage/range \\
\hline White Ethnicity (Northern European) & 114 & 120 & $95.0 \%$ \\
\hline Sex female & 62 & 125 & $49.6 \%$ \\
\hline Age at presentation (years) & $49.0(13.60)$ & 124 & $18-86$ \\
\hline$<50$ years & 61 & 124 & $49 \%$ \\
\hline$\geq 50$ years & 63 & 124 & $51 \%$ \\
\hline Currently smoking & 21 & 87 & $24 \%$ \\
\hline Ever smoking & 51 & 88 & $58 \%$ \\
\hline Colorectal cancer & 49 & 119 & $41 \%$ \\
\hline Proximal CRC & 24 & 41 & $59 \%$ \\
\hline Mean reported polyp number & $39(31.61)$ & 116 & $5-150$ \\
\hline Adenomas & 98 & 115 & $85 \%$ \\
\hline Advanced serrated polyps & 47 & 70 & $67 \%$ \\
\hline Family history of 1 st degree relative with CRC & 63 & 107 & $59 \%$ \\
\hline Family history of first or second degree relative with CRC & 66 & 91 & $73 \%$ \\
\hline
\end{tabular}

likely to have a distal cancer than were patients who presented with a CRC at 50 years or older $(60 \%$ vs. $22 \%$; $P=0.022$ ), and patients presenting before age 50 had significantly more polyps (45 vs. $34 ; P=0.03$ ). Approximately three-quarters of patients had a first- or seconddegree relative with CRC. Fifty-nine percent of the patients had a first-degree relative with CRC $(60 \%$ of females and $59 \%$ of males; $P=0.90$ ). Fifty-eight percent of participants had smoked for more than 3 months, and $24 \%$ of the participants were currently smoking. There was no difference between the sexes for current smoking status, with $22 \%$ of males and $30 \%$ of females continuing to smoke.

Many patients $(85 \%)$ had at least one polyp clearly reported as an adenoma, and CRC was significantly associated with the presence of these lesions $(P=0.03)$. Specialist pathology review was carried out by two gastrointestinal pathologists (JRJ and NIW) and serrated polyp sub-classification (common vs. advanced serrated polyps) was available on 70 patients. Approximately twothirds had at least one advanced serrated polyp, and this proportion did not differ between patients with and without CRC. Though advanced serrated polyps were more likely to arise in females and those presenting at 50 years or older, the differences did not attain statistical significance.

\section{Number of serrated polyps}

The mean reported number of hyperplastic polyps per patient was 39 (Table 2). We found no difference in mean reported polyp number by sex, CRC, between patients with and without advanced serrated polyps, (Table 3 ) or between patients from Australia and North America. Mean reported polyp count was $40 \%$ lower in patients with a first-degree relative with CRC (32, 95\% CI 26-39) compared to patients without a first-degree relative with CRC $(53,95 \%$ CI 41 64; $P=0.008$ ). Moreover, there was also a significant difference in the mean reported polyp count between the patients with any first- or second-degree relative with CRC (36, 95\% CI 29-44) and without any relative with CRC (58, 95\% CI 43-73; $P=0.003$ ). Current smokers had a higher reported polyp count (51 vs. $34 ; P=0.043$ ).

\section{Ascertainment issues}

Where information could be obtained, index cases comprised 89/122 multiple serrated polyp patients (73\%) and the characteristics of these patients and those identified due to screening $(n=32,27 \%)$ are shown in Table 4 . When gender and family history of CRC were analysed in the first presenting patient in a family, mean reported polyp count was significantly lower in females (39 vs. $48 ; P=0.047$ ) and in patients with a first-degree relative with CRC (34 vs. $55 ; P=0.026)$ though in both cases, the variance was large. Consistent with these findings, the mean reported polyp count in individuals screened because of family history was low, as was the rate of CRC in these asymptomatic patients. In three screening cases, patients were examined due to non-malignant colonic neoplasia in a relative, and all of these had relatively high polyp counts.

In 47 families, Lynch syndrome could be excluded by immunohistochemistry for mismatch repair genes coupled with $B R A F$ mutation testing. In two families, both Lynch syndrome and multiple serrated neoplasms segregated independently, and therefore family history of cancer information from these two families was not considered in 
Table 3 Univariate analyses of phenotypic features and risk factors in 126 patients

\begin{tabular}{|c|c|c|c|c|}
\hline Exposure & Number/mean (SD) & Total & Percentage/range & Significance ( $P$ value $)$ \\
\hline \multicolumn{5}{|l|}{ Age at presentation (years) } \\
\hline Females & $49(45.16)$ & 62 & $19-86$ & \multirow[t]{2}{*}{0.98} \\
\hline Males & $49(45.76)$ & 61 & $18-67$ & \\
\hline With CRC & $51(46.50)$ & 49 & $18-86$ & \multirow[t]{2}{*}{0.91} \\
\hline Without CRC & $48(44.89)$ & 68 & $19-67$ & \\
\hline \multicolumn{5}{|l|}{ Colorectal cancer } \\
\hline Females & 23 & 59 & $39 \%$ & \multirow[t]{2}{*}{0.58} \\
\hline Males & 26 & 59 & $44 \%$ & \\
\hline CRC proximal & 24 & 41 & $59 \%$ & \\
\hline Multiple proximal CRC & 9 & 24 & $38 \%$ & \multirow[t]{2}{*}{0.04} \\
\hline Multiple distal CRC & 0 & 18 & $0 \%$ & \\
\hline Female CRC-proximal & 13 & 18 & $72 \%$ & \multirow[t]{2}{*}{0.12} \\
\hline Male CRC-proximal & 11 & 23 & $48 \%$ & \\
\hline \multicolumn{5}{|l|}{ CRC Distal } \\
\hline$<50$ years of age & 12 & 20 & $60 \%$ & \multirow[t]{2}{*}{0.02} \\
\hline$\geq 50$ years of age & 4 & 19 & $22 \%$ & \\
\hline Mean reported polyp number & $39(31.61)$ & 116 & $5-150$ & \multirow{3}{*}{0.13} \\
\hline With CRC & $47(36.09)$ & 43 & $5-150$ & \\
\hline Without CRC & $35(28.50)$ & 68 & $5-150$ & \\
\hline Females & $34(27.76)$ & 56 & $5-150$ & \multirow[t]{2}{*}{0.44} \\
\hline Males & $44(34.66)$ & 59 & $5-150$ & \\
\hline Age group $<50$ years & $45(36.53)$ & 55 & $5-150$ & \multirow[t]{2}{*}{0.03} \\
\hline$\geq 50$ years & $34(25.84)$ & 59 & $5-129$ & \\
\hline With first degree relative with CRC & $32(25.65)$ & 60 & $5-150$ & \multirow[t]{2}{*}{0.008} \\
\hline Without first degree relative with CRC & $53(41.29)$ & 42 & $11-150$ & \\
\hline With any degree relative with CRC & $36(29.78)$ & 64 & $5-150$ & \multirow[t]{2}{*}{0.003} \\
\hline Without any degree relative with $\mathrm{CRC}$ & $58(36.58)$ & 25 & $11-129$ & \\
\hline \multicolumn{5}{|l|}{ Smoking } \\
\hline Current & $51(37.95)$ & 21 & $5-129$ & \multirow[t]{2}{*}{0.43} \\
\hline Not currently smoking & $34(28.41)$ & 66 & $5-150$ & \\
\hline Ever & $41(31.53)$ & 52 & $5-129$ & \multirow[t]{2}{*}{0.56} \\
\hline Never & $32(30.52)$ & 37 & $5-150$ & \\
\hline \multicolumn{5}{|l|}{ Adenomas } \\
\hline $\mathrm{CRC}$ & 42 & 43 & $98 \%$ & \multirow[t]{2}{*}{0.03} \\
\hline Without CRC & 54 & 67 & $81 \%$ & \\
\hline \multicolumn{5}{|l|}{ Advanced serrated polyps } \\
\hline $\mathrm{CRC}$ & 19 & 28 & $68 \%$ & \multirow[t]{2}{*}{0.92} \\
\hline Without CRC & 26 & 39 & $67 \%$ & \\
\hline Females & 28 & 38 & $74 \%$ & \multirow[t]{2}{*}{0.44} \\
\hline Males & 21 & 33 & $64 \%$ & \\
\hline$<50$ years of age & 19 & 31 & $51 \%$ & \multirow[t]{2}{*}{0.31} \\
\hline$\geq 50$ years of age & 27 & 37 & $73 \%$ & \\
\hline
\end{tabular}

this study. These two families have been described in detail as case reports elsewhere [25].

\section{Polyp number category}

Seventy-three percent $(n=66)$ had a reported number of between five and 79 serrated polyps (moderate polyposis), and the remainder had 80 or more (dense polyposis;
Table 5). Females were significantly under-represented in the dense polyposis group $(P=0.02)$. Family history of CRC was inversely associated with polyp count category with the dense polyposis group having significantly less family history than those with moderate polyposis $(P=$ 0.049). Though the rate of CRC did not differ between the two groups, patients presenting with CRC in the dense polyposis group were more likely to have a distal CRC. In 
Table 4 Comparison of case characteristics according to ascertainment (index vs. screening cases)

\begin{tabular}{|c|c|c|c|c|c|}
\hline Variable & & Number $(\%)$ Index case & $P$ value & Number (\%) Screening case & $P$ value \\
\hline \multirow[t]{2}{*}{ Gender } & Male & $49(55)$ & & $13(41)$ & \\
\hline & Female & $40(45)$ & NA & $19(59)$ & 0.22 \\
\hline \multirow[t]{2}{*}{ CRC } & Yes & $37(43)$ & & $09(31)$ & \\
\hline & No & $48(57)$ & NA & $20(69)$ & 0.28 \\
\hline \multirow[t]{2}{*}{ FDR with CRC } & Yes & $36(48)$ & & $24(88)$ & \\
\hline & No & $39(52)$ & NA & $03(12)^{\mathrm{a}}$ & $0.0002^{\mathrm{b}}$ \\
\hline Variable & & Mean (SD) & & Mean (SD) & \\
\hline Age & & $48(14)$ & NA & $50(12)$ & 0.49 \\
\hline Mean polyp count & & $44(34)$ & NA & $27(21)$ & 0.048 \\
\hline Mean polyp count & Male & $48(36)$ & 0.047 & $27(20)$ & 0.82 \\
\hline Mean polyp count & Female & $39(30)$ & & $26(22)$ & \\
\hline Mean polyp count & FDR with CRC & $34(28)$ & 0.026 & $26(19)$ & 0.49 \\
\hline Mean polyp count & No FDR with CRC & $55(37)$ & & $43(29)$ & \\
\hline
\end{tabular}

${ }^{\text {a }}$ Cases screened due to family history of colonic neoplasia (non-malignant, $n=3$ )

${ }^{\mathrm{b}} P$ value from two-sided Fisher's exact test

contrast, proximal CRC predominated in the moderate polyposis group. Patients who met WHO criterion 3 for HPS ( $>30$ hyperplastic polyps) were also significantly less likely to have a family history of CRC $(P=0.04)$, though no male predominance was seen, nor were distal CRC more common. Current smokers were more prevalent in the higher polyp count categories for both classifications but this was not statistically significant $(P=0.39$ and 0.44$)$. Multivariate analysis indicated that both the male predom- inance and the lack of family history of CRC were independent predictors of dense polyposis (Table 6).

\section{Discussion}

In this study, we examined the spectrum of phenotypic features in a large group of patients with multiple serrated polyps recruited from genetics clinics. Our results demon-
Table 5 Univariate analysis of risk variables for a moderate or dense serrated polyp count in the index cases

\footnotetext{
${ }^{a}$ Independent samples $t$ test for comparison of age at presentation between moderate and dense polyp groups

${ }^{\mathrm{b}} P$ value from two-sided Fisher's exact test
}

\begin{tabular}{|c|c|c|c|}
\hline & \multirow{3}{*}{$\begin{array}{l}\text { Moderate (5-79 polyps) } \\
n=66 \\
\text { Mean (SD) }\end{array}$} & \multicolumn{2}{|c|}{ Dense ( 80 polyps or more) } \\
\hline & & \multicolumn{2}{|l|}{$n=14$} \\
\hline & & Mean (SD) & $P$ value \\
\hline \multirow[t]{2}{*}{ Age (years) } & $48.2(13.6)$ & $44.5(15.1)$ & $0.36^{\mathrm{a}}$ \\
\hline & $N(\%)$ & $N(\%)$ & OR $(95 \% \mathrm{CI}), P$ value \\
\hline \multicolumn{4}{|l|}{ Gender } \\
\hline Female & $34(50 \%)$ & $2(14 \%)$ & $6.0(1.25-28.86)$ \\
\hline Male & $34(50 \%)$ & $12(86 \%)$ & $0.018^{\mathrm{b}}$ \\
\hline \multicolumn{4}{|l|}{ CRC } \\
\hline No & $41(64 \%)$ & $6(43 \%)$ & $2.38(0.73-7.7)$ \\
\hline Yes & $23(36 \%)$ & $8(57 \%)$ & $0.23^{\mathrm{b}}$ \\
\hline \multicolumn{4}{|l|}{ CRC Site } \\
\hline Proximal & $13(62 \%)$ & $1(17 \%)$ & $8.13(0.79-82.73)$ \\
\hline Distal & $8(38 \%)$ & $5(83 \%)$ & $0.077^{\mathrm{b}}$ \\
\hline \multicolumn{4}{|c|}{ First degree relative with $\mathrm{CRC}$} \\
\hline No & $27(47 \%)$ & $10(77 \%)$ & $0.26(0.07-1.05)$ \\
\hline Yes & $31(53 \%)$ & $3(23 \%)$ & $0.066^{\mathrm{b}}$ \\
\hline \multicolumn{4}{|c|}{ First or second degree relative with CRC } \\
\hline No & $16(29 \%)$ & $8(62 \%)$ & $0.25(0.07-0.88)$ \\
\hline Yes & $40(71 \%)$ & $5(38 \%)$ & $0.049^{\mathrm{b}}$ \\
\hline
\end{tabular}


Table 6 Logistic regression analysis of putative predictors of a dense serrated polyp count in the index cases only

\begin{tabular}{lllll}
\hline Dense polyp group (80-150 polyps) & OR & \multicolumn{2}{l}{$95 \%$ Confidence interval } & Upper \\
\cline { 3 - 4 } & & Lower & 57.12 \\
Male gender & 9.5 & 1.58 & 0.87 \\
First degree relative with CRC & 0.17 & 0.033 & 0.034 \\
Occurrence of CRC & 1.94 & 0.44 & 8.56 \\
\hline
\end{tabular}

The moderate polyp group (5-79 polyps) was the reference group with age, ethnicity, and recruitment site included as co-variates in the final analysis of main effects

strate significant phenotypic heterogeneity and suggest that both personal and familial risks of CRC in these patients are associated with multiple factors.

Multiple serrated polyp patients demonstrated a high level of CRC risk, with $41 \%$ of participants presenting with $\mathrm{CRC}$, a figure consistent with the findings of multiple reports [9-11, 16, 17, 19, 20, 22]. In contrast, two reports have suggested that HPS is not associated with an increased risk of CRC $[15,21]$. This may reflect variation in the prevalences and exposures of genetic and environmental risk factors, respectively, within these local populations. Though polyp numbers were higher in patients with CRC [12], neither polyp numbers, nor the presence of advanced serrated polyps significantly determined whether a patient presented with CRC. Consistent with a previous report however, CRC was significantly associated with the presence of adenomas [20]. Dysplasia in co-existing polyps has also been reported previously as a risk factor for CRC [17]. Adenomas are common in the general population and it is likely that the factors which contribute to the growth and development of serrated polyps in these patients also act to increase the growth of a limited number of micro-adenomas [26].

CRC arose in the proximal colon more often than would be expected [27], with proximal cancers arising more frequently in females. A high rate of multiple synchronous CRCs was observed, with multiplicity significantly more common in the proximal colon when compared to the distal colon. In CRC arising via the serrated pathway, multiplicity and proximal location have been previously reported as associations [27, 28]. However, in patients less than 50 years, CRCs were more likely to be distal, which has been reported recently as a feature of young-onset CRC in general [29]. One of the largest HPS series reported to date (38 patients with a mean age at presentation of 44 years) found that $60 \%$ of CRC arose in distal sites [9]. This is an important finding as the emphasis placed on the proximal colon by the current WHO criteria may serve to distract from the risk of CRC in the young onset patient with multiple distal lesions whose presentation falls short of the current criteria.
A slight male preponderance of $58 \%$ can be calculated overall from the published reports on HPS [9-11, 13, 14, 16-22, 30], and notably the St. Mark's study of 1980 suggested that HPS was a disorder of young males [21]. No evidence of a male bias for multiple serrated polyps was observed in our 126 patients, displaying an approximately equal sex ratio when analysed overall. However, considerable differences were observed when this group of multiple serrated polyp patients was stratified. The group with the highest polyp numbers and the fewest relatives affected with CRC was predominantly male, and this is consistent with at least two previous reports, and may explain the results of the St. Mark's series of 1980 [21]. The question arises as to whether these two results regarding gender and family history of CRC might reflect ascertainment bias. It could be postulated that individuals screened because of $\mathrm{CRC}$ in a relative may be more likely to have a lower polyp count because they are asymptomatic, and females may be more likely to present for screening. However, relationships between polyp count and both gender and family history of CRC demonstrated this same pattern when only index cases were examined. As would therefore be expected, asymptomatic cases screened because of family history of colonic neoplasia demonstrated lower polyp counts and a low rate of CRC.

In this study, we found a significant increase in polyp numbers associated with direct current exposure to cigarette smoke, and suggests that rather than having a causal role in HPS, smoke exposure may be associated with modulation of phenotype, as manifested by increased polyp numbers. This enhancement of phenotype was not unexpected as population-based studies have consistently shown that the association between smoking and colorectal cancer was largely due to the strong effect of smoking on the subset of CRC which arose through the serrated neoplasia pathway [10, 31-33]. Smokers are more likely to present with hyperplastic polyps, even in asymptomatic individuals [34], with the most significant association between smokers and serrated neoplasia in the population having both hyperplastic and adenomatous polyps [35-37], a phenotype shared with individuals with HPS. As has been demonstrated in 
this report, multiple serrated polyps and CRC in a background of multiple serrated polyps, both can occur in the absence of smoking further supporting the premise that smoking is likely to be a modifier of phenotype rather than a causal factor. The two most significant predictors of increased polyp number were male sex and lack of family history of CRC, and this was independent of smoking status.

A family history of CRC in first-degree relatives has been reported in HPS by several authors [9-11, 19]. In our study, patient recruitment was effected through high-risk clinics, rather than through population-based screening, and even though our findings for the rate of first-degree relatives with CRC however are completely consistent with an independent large series from the UK describing 32 HPS patients [13], this method of recruitment is likely to have inflated the risk of having affected relatives. Importantly, $40 \%$ of the patients in this study did not have a first-degree relative with CRC, suggesting that patients with multiple serrated polyps from genetics clinics are equally likely to be referred in the absence of a first-degree family history of CRC. Our current study demonstrated that family history of CRC was relatively low in the group of patients with very high polyp counts, thus highlighting the possibility of genetic heterogeneity as a basis for the phenotypic variation observed in this condition. Though this finding emerged from a stratified analysis, separation of the predispositions was incomplete; suggesting that predisposition to serrated neoplasia may be a complex genetic condition.

In summary, our data support the notion, previously proposed by multiple authors $[6,10,30,38,39]$, that patients with multiple serrated polyps have a heterogeneous condition. The clinical importance in identifying HPS is highlighted by the observation that $40 \%$ of HPS patients in our cohort presented with CRC, frequently in the proximal colon with an increased risk of multiplicity. Also of clinical importance is the risk of CRC in relatives which is likely to exceed that of the population, though quantitation of this risk remains problematical $[6,39]$. The study demonstrated that young-onset patients with multiple serrated polyps are more likely to develop a distal CRC despite the emphasis placed on proximal disease by the WHO criteria. Importantly, the study has presented evidence for consideration potentially highlighting heterogeneity in the mode of inheritance of serrated polyp predisposition, with the identification of a younger-onset group with highest polyp counts, male gender and little family history of CRC, features alluded to in an influential publication in 1980 [21]. The novel finding that family history varies inversely with polyp count and gender, is unlikely to be confounded by age, and is independent of ascertainment and smoking, and suggests that patients with multiple serrated polyps have a complex condition modified by a multitude of genetic, environmental, and sex-specific factors. The development of new clinical criteria with a biological basis [13] to better define this predisposition and to identify those with the highest personal and familial risks of CRC are warranted.

Acknowledgments This work was supported by grants from the Cancer Council Queensland, the Hicks Foundation in Victoria, and the National Cancer Institute 1R01CA123010 (Genetics of Serrated Neoplasia). The content of this manuscript does not necessarily reflect the views or policies of the National Cancer Institute nor does mention of trade names, commercial products, or organisations imply endorsement by the US Government. JY is a Cancer Council Queensland Senior Research Fellow. MD and EC were Hicks Foundation in Victoria Fellows.

Declaration The authors have no conflict of interest to declare with respect to this manuscript.

Open Access This article is distributed under the terms of the Creative Commons Attribution Noncommercial License which permits any noncommercial use, distribution, and reproduction in any medium, provided the original author(s) and source are credited.

\section{References}

1. Kampman E (2007) A first-degree relative with colorectal cancer: what are we missing? Cancer Epidemiol Biomarkers Prev 16:1-3

2. Sinicrope FA (2005) Insights into familial colon cancer: the plot thickens. Clin Gastroenterol Hepatol 3:216-217

3. Spjut H, Estrada RG (1977) The significance of epithelial polyps of the large bowel. Pathol Annu 12(Pt 1):147-170

4. Young J, Jenkins M, Parry S, Young B, Nancarrow D, English D, Giles G, Jass J (2007) Serrated pathway colorectal cancer in the population: genetic consideration. Gut 56:1453-1459

5. Burt R, Jass JR (2000) Hyperplastic polyposis. In: Hamilton SR, Aaltonen LA (eds) Pathology and genetics of tumours of the digestive system. IARC Press, Lyon, pp 135-136

6. Jass JR (2008) Colorectal polyposes: from phenotype to diagnosis. Pathol Res Prac 204(7):431-447

7. Young J, Barker MA, Simms LA, Walsh MD, Biden KG, Buchanan D, Buttenshaw R, Whitehall VL, Arnold S, Jackson L, Kambara T, Spring KJ, Jenkins MA, Walker GJ, Hopper JL, Leggett BA, Jass JR (2005) Evidence for BRAF mutation and variable levels of microsatellite instability in a syndrome of familial colorectal cancer. Clin Gastroenterol Hepatol 3:254-263

8. Higuchi T, Jass JR (2004) My approach to serrated polyps of the colorectum. J Clin Pathol 57:682-686

9. Chow E, Lipton L, Lynch E, D’Souza R, Aragona C, Hodgkin L, Brown G, Winship I, Barker M, Buchanan D, Cowie S, Nasioulas S, du Sart D, Young J, Leggett B, Jass J, Macrae F (2006) Hyperplastic polyposis syndrome: phenotypic presentations and the role of MBD4 and MYH. Gastroenterology 131:30-39

10. Rashid A, Houlihan PS, Booker S, Petersen GM, Giardiello FM, Hamilton SR (2000) Phenotypic and molecular characteristics of hyperplastic polyposis. Gastroenterology 119:323-332

11. Hyman NH, Anderson P, Blasyk H (2004) Hyperplastic polyposis and the risk of colorectal cancer. Dis Colon Rectum 47:21012104

12. Boparai KS, Mathus-Vliegen EM, Koornstra JJ, Nagengast FM, van Leerdam M, van Noesel CJ, Houben M, Cats A, van Hest LP, 
Fockens P, Dekker E (2009) Increased colorectal cancer risk during follow-up in patients with hyperplastic polyposis syndrome: a multicentre cohort study. Gut

13. Carvajal-Carmona LG, Howarth KM, Lockett M, PolancoEcheverry GM, Volikos E, Gorman M, Barclay E, Martin L, Jones AM, Saunders B, Guenther T, Donaldson A, Paterson J, Frayling I, Novelli MR, Phillips R, Thomas HJ, Silver A, Atkin W, Tomlinson IP (2007) Molecular classification and genetic pathways in hyperplastic polyposis syndrome. J Pathol 212:378-385

14. Bengoechea O, Martinez-Penuela JM, Larrinaga B, Valerdi J, Borda F (1987) Hyperplastic polyposis of the colorectum and adenocarcinoma in a 24-year-old man. Am J Surg Pathol 11:323-327

15. Ferrandez A, Samowitz W, DiSario JA, Burt RW (2004) Phenotypic characteristics and risk of cancer development in hyperplastic polyposis: case series and literature review. Am J Gastroenterol 99:2012-2018

16. Lage P, Cravo M, Sousa R, Chaves P, Salazar M, Fonseca R, Claro I, Suspiro A, Rodrigues P, Raposo H, Fidalgo P, NobreLeitao C (2004) Management of Portuguese patients with hyperplastic polyposis and screening of at-risk first-degree relatives: a contribution for future guidelines based on a clinical study. Am J Gastroenterol 99:1779-1784

17. Leggett BA, Devereaux B, Biden K, Searle J, Young J, Jass J (2001) Hyperplastic polyposis: association with colorectal cancer. Am J Surg Pathol 25:177-184

18. Place RJ, Simmang CL (1999) Hyperplastic-adenomatous polyposis syndrome. J Am Coll Surg 188:503-507

19. Renaut AJ, Douglas PR, Newstead GL (2002) Hyperplastic polyposis of the colon and rectum. Colorectal Dis 4:213-215

20. Rubio CA, Stemme S, Jaramillo E, Lindblom A (2006) Hyperplastic polyposis coli syndrome and colorectal carcinoma. Endoscopy 38:266-270

21. Williams GT, Arthur JF, Bussey HJ, Morson BC (1980) Metaplastic polyps and polyposis of the colorectum. Histopathology 4:155-170

22. Yeoman A, Young J, Arnold J, Jass J, Parry S (2007) Hyperplastic polyposis in the New Zealand population: a condition associated with increased colorectal cancer risk and European ancestory. NZMJ 120:31-39

23. Jass JR (2005) Serrated adenoma of the colorectum and the DNAmethylator phenotype. Nat Clin Prac 2:398-405

24. Sweet K, Willis J, Zhou XP, Gallione C, Sawada T, Alhopuro P, Khoo SK, Patocs A, Martin C, Bridgeman S, Heinz J, Pilarski R, Lehtonen R, Prior TW, Frebourg T, Teh BT, Marchuk DA, Aaltonen LA, Eng C (2005) Molecular classification of patients with unexplained hamartomatous and hyperplastic polyposis. Jama 294:2465-2473

25. Walsh MD, Buchanan DD, Walters R, Roberts A, Arnold S, McKeone D, Clendenning M, Ruszkiewicz AR, Jenkins MA, Hopper JL, Goldblatt J, George J, Suthers GK, Phillips K, Young GP, Macrae F, Drini M, Woods MO, Parry S, Jass JR, Young JP (2009) Analysis of families with Lynch syndrome complicated by advanced serrated neoplasia: the importance of pathology review and pedigree analysis. Fam Can 8(4):313-323
26. Jass JR (1983) Relation between metaplastic polyp and carcinoma of the colorectum. Lancet 1:28-30

27. Jass JR, Do KA, Simms LA, Iino H, Wynter C, Pillay SP, Searle J, Radford-Smith G, Young J, Leggett B (1998) Morphology of sporadic colorectal cancer with DNA replication errors. Gut 42:673-679

28. Jeevaratnam P, Cottier DS, Browett PJ, Van De Water NS, Pokos V, Jass JR (1996) Familial giant hyperplastic polyposis predisposing to colorectal cancer: a new hereditary bowel cancer syndrome. J Pathol 179:20-25

29. Yantiss RK, Goodarzi M, Zhou XK, Rennert H, Pirog EC, Banner BF, Chen YT (2009) Clinical, pathologic, and molecular features of early-onset colorectal carcinoma. Am J Surg Pathol 33:572582

30. Torlakovic E, Snover DC (1996) Serrated adenomatous polyposis in humans. Gastroenterology 110:748-755

31. Samowitz WS, Albertsen H, Sweeney C, Herrick J, Caan BJ, Anderson KE, Wolff RK, Slattery ML (2006) Association of smoking, $\mathrm{CpG}$ island methylator phenotype, and V600E BRAF mutations in colon cancer. J Natl Cancer Inst 98:1731-1738

32. Slattery ML, Curtin K, Anderson K, Ma KN, Ballard L, Edwards S, Schaffer D, Potter J, Leppert M, Samowitz WS (2000) Associations between cigarette smoking, lifestyle factors, and microsatellite instability in colon tumors. J Natl Cancer Inst 92:1831-1836

33. Slattery ML, Curtin K, Sweeney C, Levin TR, Potter J, Wolff RK, Albertsen H, Samowitz WS (2007) Diet and lifestyle factor associations with $\mathrm{CpG}$ island methylator phenotype and BRAF mutations in colon cancer. Int J Cancer 120:656-663

34. Peppone LJ, Mahoney MC, Cummings KM, Michalek AM, Reid ME, Moysich KB, Hyland A (2008) Colorectal cancer occurs earlier in those exposed to tobacco smoke: implications for screening. J Cancer Res Clin Oncol 134(7):743-751

35. Ji BT, Weissfeld JL, Chow WH, Huang WY, Schoen RE, Hayes RB (2006) Tobacco smoking and colorectal hyperplastic and adenomatous polyps. Cancer Epidemiol Biomarkers Prev 15:897901

36. Morimoto L, Newcomb P, Ulrich C, Bostick R, Lais C, Potter J (2002) potential? Rffhaapefm. Risk factors for hyperplastic and adenomatous polyps: evidence for malignant potential? Cancer Epidemiol Biomarkers Prev 11:1012-1018

37. Shrubsole MJ, Wu H, Ness RM, Shyr Y, Smalley WE, Zheng W (2008) Alcohol drinking, cigarette smoking, and risk of colorectal adenomatous and hyperplastic polyps. Am J Epidemiol 167 (9):1050-1058

38. Burt RW, Samowits WS (1996) Serrated adenomatous polyposis: a new syndrome? Gastroenterology 110:950-952

39. Jass JR (2007) Gastrointestinal polyposes: clinical, pathological and molecular features. Gastroenterol Clin North Am 36:927-946, viii

40. Yeoman A, Young J, Arnold J, Jass J, Parry S (2007) Hyperplastic polyposis in the New Zealand population: a condition associated with increased colorectal cancer risk and European ancestry. N Z Med J 120:U2827 